\title{
Influence of gaseous pollutants and their synergistic effects on the aging of reflector materials for concentrating solar thermal technologies
}

\author{
A. García-Segura ${ }^{a, *}$, A. Fernández-García ${ }^{a}$, M.J. Ariza ${ }^{b}$, F. Sutter ${ }^{c}$, T.C. Diamantino ${ }^{\text {, }}$ \\ L. Martínez-Arcos ${ }^{\text {a }}$, T.J. Reche-Navarro ${ }^{c}$, L. Valenzuela $^{\mathrm{a}}$ \\ ${ }^{a}$ CIEMAT, Plataforma Solar de Almería, Ctra. Senés, km 4, P.O. Box 22, 04200, Tabernas, Almería, Spain \\ ${ }^{\mathrm{b}}$ Universidad de Almería, Física Aplicada, CITE II-A, 04120, Almería, Spain \\ ${ }^{\mathrm{c}}$ DLR, German Aerospace Center, Institute of Solar Research, Plataforma Solar de Almería, Ctra. Senés, km 4, P.O. Box 39, 04200, Tabernas, Almería, Spain \\ ${ }^{\mathrm{d}}$ LNEG, National Laboratory of Energy and Geology, Estrada do Paço do Lumiar, 22, E, r/c, 1649-038, Lisbon, Portugal
}

\section{A R T I C L E I N F O}

\section{Keywords:}

Concentrating solar thermal technology

Solar reflector

Durability test

Multicomponent gas mixture

Synergistic effect

Acceleration factor

\begin{abstract}
A B S T R A C T
Concentrating solar thermal technologies have experienced an important boost in the last few years. Besides the production of electricity, they are particularly useful for the supply of industrial process heat. The industrial atmospheres affecting these solar plants typically contain gaseous pollutants that are likely to promote corrosion on the components of the solar facility, specifically solar reflectors, thereby compromising their optimal performance and the overall system efficiency. Seven accelerated aging tests were designed to study the effects of three air pollutants $\left(\mathrm{H}_{2} \mathrm{~S}, \mathrm{SO}_{2}\right.$ and $\left.\mathrm{NO}_{2}\right)$ on the durability of two commercially available reflector types (silveredglass and aluminum), both in single-gas tests and in multicomponent gas mixtures. Additionally, the same material types were exposed outdoors at five representative polluted sites, including industrial, urban and coastal environments. Reflectance and optical microscope monitoring corroborated which degree of corrosion was developed on a specific type of reflector in the different tests with gaseous pollutants, as well as the synergistic effects of gas combinations. For example, tests with sulfur were harmful for silvered-glass reflectors (up to a total of 16 corrosion spots), whereas aluminum was particularly affected by tests with $\mathrm{NO}_{2}$ (numerous micro spots of around $50 \mu \mathrm{m}$ size). Moreover, comparisons of the corrosion patterns found in accelerated-aging and outdoor exposures revealed which laboratory test reproduced the different real polluted atmospheres in the most realistic way, which is the main goal of this work. For instance, the degradation found at Site 2 was reproduced by Test $\mathrm{NO}_{2}+\mathrm{SO}_{2}$, with an acceleration factor of 27 .
\end{abstract}

\section{Introduction}

The deployment of concentrating solar thermal (CST) technologies has experienced a noteworthy increase in the past few years [1]. Whether for the production of electricity in concentrating solar power (CSP) plants or for the supply of industrial process heat (IPH), CST applications are considered a major renewable and environmentally friendly contributor to the energy mix [2]. One of the main challenges that CST facilities must face is the maintenance of their components' optimal properties over time. Specifically, the reliable performance of solar reflectors is a vital aspect to maintain high conversion efficiency from solar to thermal in a concentrating solar system [3], which may be compromised if the solar facility is located near an industrial site.
Corrosive atmospheres typically found near industries are known to interact with the reflective layer of solar reflectors and cause their degradation [4]. Some of the most deleterious gaseous pollutants for the reflective metals of solar reflectors (i.e. silver/copper or aluminum) and their corresponding industrial origins are summarized in Table 1 [5].

The significant influence of airborne pollutants has been previously identified and studied in other materials, such as the metallic absorber components of solar thermal collectors [6-9], and also the main corrosion products resulting from the exposure of both silver $[10,11]$ and copper [12,13] to different polluted atmospheres have been recently characterized. Specifically, it has been highlighted the importance of studying the degradation of solar reflectors in industrial sites due to

\footnotetext{
* Corresponding author.

E-mail addresses: agarcia@psa.es (A. García-Segura), afernandez@psa.es (A. Fernández-García), mjariza@ual.es (M.J. Ariza), florian.sutter@dlr.de (F. Sutter), teresa.diamantino@lneg.pt (T.C. Diamantino), lucia.martinez@psa.es (L. Martínez-Arcos), tomasjesus.rechenavarro@dlr.de (T.J. Reche-Navarro), loreto.valenzuela@psa.es (L. Valenzuela).
} 